\title{
Effect of right bundle branch block on in-hospital mortality in patients with heart failure
}

\author{
Ante Matana ${ }^{1 *}$, Luka Zaputović1, Teodora Zaninović Jurjević ${ }^{1}$, Alen Ružić', Daniela Malić1, \\ Ivana Smoljan', Nikolina Jurjevićc ${ }^{2}$ Lea Skorup ${ }^{3}$, Marko Marinović ${ }^{2}$ \\ 'University of Rijeka School of Medicine, University Hospital Centre Rijeka, Rijeka, Croatia \\ ${ }^{2}$ University of Rijeka School of Medicine, Rijeka, Croatia \\ ${ }^{3}$ Department of Emergency Medicine of County of Primorje-Gorski kotar, Rijeka, Croatia
}

Goal: The prognostic significance of right bundle branch block (RBBB) in hospitalized heart failure (HF) patients is unclear. Hence, we sought to determine its prognostic value during hospital stay in patients admitted for HF.

Patients and Methods: The study population consisted of the patients treated for HF in Department of Cardiovascular Diseases, University Hospital Centre Rijeka, from 2006 to 2012. Many variables were compared between group without BBB (G1), with left BBB (G2) and with RBBB (G3). Also, the same variables were compared in $\mathrm{G} 3$ between patients who were discharged alive and those deceased.

Results: There were totally 1820 patients (aged 75.1 \pm 10.1 ;

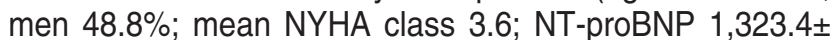
$1,673.7 \mathrm{pmol} / \mathrm{L}$; echocardiography in $73.4 \%$ ). G1 consisted

\footnotetext{
Received: $19^{\text {th }}$ Apr 2014

*Address for correspondence: Ante Matana, Ivana Luppisa 13, HR-51000 Rijeka, Croatia.

Phone: +385-91-798-5118

E-mail: ante.matana@gmail.com
}

of $1380(75.8 \%)$, G2 of $275(15.1 \%)$ and G3 of $165(9.1 \%)$ patients. G3 patients were older than $\mathrm{G} 2$ and $\mathrm{G} 1$ patients, with fewer women and slower heart rate (HR). Mean NYHA class was 3.7 in G3 and G2 and 3.6 in G1, with NT-proBNP value higher in $\mathrm{G} 3$ and $\mathrm{G} 2$ than in $\mathrm{G} 1$. The lowest left ventricular ejection fraction (EF) was found in $\mathrm{G} 2$, with no difference between G3 and G1. Serum urea and creatinine were higher in G3 and G2 than in G1, and chronic obstructive lung disease was more frequent in G1. Mortality in G1, G2 and G3 was $14.3 \%, 19.6 \%$ and $20.6 \%$, respectively. Deceased patients in G3 were older, with lower blood pressure, glomerular filtration rate and $E F$, and with higher $\mathrm{HR}$, troponin, NYHA class, NT-proBNP, urea and creatinine values than in survivors.

Conclusion: The in-hospital mortality in HF patients with RBBB was as high as in those with LBBB and significantly higher than in patients without bundle branch block. In these patients, older age, lower blood pressure and EF, poorer renal function and higher HR, NYHA class, troponin and NTproBNP may additionally cause adverse hospital outcome.

KEYWORDS: right bundle branch block, heart failure, mortality.

CITATION: Cardiol Croat. 2014;9(5-6):227

\section{Literature}

1. Barsheshet A, Leor J, Goldbourt U, et al. Effect of bundle branch pattern on mortality in hospitalized patients with heart failure. Am J Cardiol. 2008;101:1303-8

2. Abdel-Qadir HM, Tu JV, Austin PC, Wang JT, Lee DS. Bundle branch block patterns and long-term outcomes in heart failure. Int J Cardiol. 2011;146:213-8.

3. Barsheshet A, Goldenberg I, Garty M, et al. Relation of bundle branch block to long-term (four year) mortality in hospitalized patients with systolic heart failure. Am J Cardiol. 2011;107:540-4 